\title{
Investigation of nucleation events vertical extent: a long term study at two different altitude sites
}

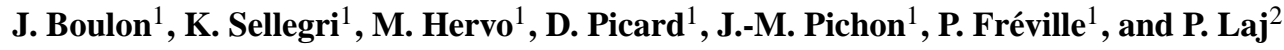 \\ ${ }^{1}$ Laboratoire de Météorologie Physique CNRS UMR6016, Observatoire de Physique du Globe de Clermont-Ferrand, \\ Université Blaise Pascal, France \\ ${ }^{2}$ Laboratoire de Glaciologie et Géophysique de l'Environnement, CNRS UMR5183, Saint Martin d'Héres, France
}

Received: 17 February 2011 - Published in Atmos. Chem. Phys. Discuss.: 10 March 2011

Revised: 3 June 2011 - Accepted: 7 June 2011 - Published: 20 June 2011

\begin{abstract}
In this work we present an analysis of the occurrence of nucleation events during more than three years of measurements at two different rural altitude sites, the puy de Dôme research station (1465 ma.s.1.) and the Opme station $(660 \mathrm{~m}$ a.s.l.), central France. The collected database is a unique combination of scanning mobility particle sizer (10-400 nm), air ion spectrometers (from 0.8 to $42 \mathrm{~nm}$ for NTP-conditions), and, neutral clusters and air ion spectrometers (from 0.8 to $42 \mathrm{~nm}$ for NTP-conditions) measurements at these two different altitudes nearly located research stations, from February 2007 to June 2010. The seasonality of the frequency of nucleation events was studied at the puy de Dôme station and maximum of events frequency was found during early spring and early autumn. During the measurement period, neither the particle formation rates $\left(\bar{J}_{2}=1.382 \pm 0.195 \mathrm{~s}^{-1}\right)$ nor the growth rates $\left(\overline{G R}_{1.3-20 \mathrm{~nm}}=6.20 \pm 0.12 \mathrm{~nm} \mathrm{~h}^{-1}\right)$ differ from one site to the other on average. Hovewer, we found that, on 437 sampling days in common to the two sites, the nucleation frequency was higher at the puy de Dôme station (35.9\%, 157 days) than at the low elevation station of Opme (20.8\%, 91 days). LIDAR measurements and the evolution of the potential equivalent temperature revealed that the nucleation could be triggered either (i) within the whole low tropospheric column at the same time from the planetary boundary layer to the top of the interface layer $(29.2 \%, 47$ events), (ii) above the planetary boundary layer upper limit $(43.5 \%$, 70 events), and (iii) at low altitude and then transported, conserving dynamic and properties, at high altitude ( $24.8 \%$, 40 events). This is the first time that the vertical extent of nucleation can be studied over a long observational period, allowing for a rigorous statistical analysis of the occurrence of nucleation over the whole lower troposphere. This work
\end{abstract}

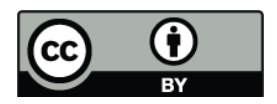

Correspondence to: J. Boulon (j.boulon@opgc.univ-bpclermont.fr) highlights the fact that nucleation can occur over a large vertical extent, at least the whole low tropospheric column, and also the fact that it occurs twice as frequently as actually detected in the planetary boundary layer. The role of sulfuric acid and ions in the nucleation process was investigated at the altitude station and no correlation was found between nucleation events and the estimated sulfuric acid concentrations. However, the contribution of ion-induced nucleation was found to be relatively high $(12.49 \pm 2.03 \%$ of the total nucleation rate).

\section{Introduction}

The formation of new ultrafine particles from the gas phase has been observed in various continental and marine locations (see for a review Kulmala et al., 2004) indicating that nucleation followed by new particle formation (NPF) events is an ubiquitous phenomenon in the planetary boundary layer (PBL). Up to which altitude these NPF events take place, and where they are initiated is still under debate. Crumeyrolle et al. (2010) observed during airborne measurements that NPF events was limited to the PBL vertical extent while Hamburger et al. (2010) have evidenced high concentrations of ultrafine particles in the upper free troposphere. Several studies show that atmospheric dynamics such as turbulence or boundary layer mixing could trigger the nucleation process (i.e. Nilsson and Kulmala, 1998; Nilsson et al., 2001). In a more long term study, Komppula et al. (2003) have shown that the new particle formation was occurring at two different low altitude sites (340 and $560 \mathrm{~m}$ a.s.l.). During the intensive field campaign SATURN, Stratmann et al. (2003) showed that nucleation could take place inside the residual layer and that it could be induced by the breakup of the nocturnal inversion. Furthermore, they explained the ultrafine particle concentration at a ground-based measurement site as a result of the mixing down of the freshly

Published by Copernicus Publications on behalf of the European Geosciences Union. 
formed particles within the residual layer. A recent intensive field campaign using LIDAR soundings coupled with 12 helicopter particle measurement flights confirm that the new particle formation process is enhanced in layers of high turbulent mixing such as the residual layer (Wehner et al., 2010). Wehner and co workers also showed that the NPF reported to occur in the residual layer are connected to peaks of ultrafine particle number concentrations at the ground level (Cabauw, Netherlands). Those previous studies are based on few cases (less than twenty) and most of them use particle measurement devices that allow measurement down to $3 \mathrm{~nm}$. Atmospheric research station located at mountain sites may lay at the interface between the low and the high troposphere. Although there might be some bias at mountain sites due to the distortion of the air flow because of the topography, they provide statistical information that can not be obtained from airborne studies. The bias due to the topography can however be indirectly evaluated by analyzing the LIDAR vertical profile in regard to the in situ measurements. Here, we propose the first long term study of the vertical extent of the new particle formation process based on a nearly 4-yr measurement period at two different altitudes: The puy de Dôme station (1465 m a.s.l.) and the Opme station (660 m a.s.1.). Both sites were equipped with instruments which allow ions and neutral particle detection from 3.2 to $0.0013 \mathrm{~cm}^{2} \mathrm{~V}^{-1} \mathrm{~s}^{-1}$, corresponding to Stokes-Millikan mobility diameters (Mäkelä et al., 1996) between 0.8 and $42 \mathrm{~nm}$ in NTP-conditions. Hence, it allows the tracking of in situ nucleation versus transport from one site to the other. In addition to particle measurement devices, the atmospheric vertical structure and the boundary layer evolution was investigated using LIDAR measurements that were operated at about $11 \mathrm{~km}$ of each measurement sites.

\section{Measurement sites}

Measurements were conducted at two nearly located midaltitude sites: the puy de Dôme station (mountain site) and Opme station (rural site).

The puy de Dôme research station (PdD) is located at $1465 \mathrm{~m}$ a.s.l. in central France $\left(45^{\circ} 46^{\prime} \mathrm{N}, 2^{\circ} 57^{\prime} \mathrm{E}\right)$. The station is surrounded mainly by a protected area where fields and forests are predominant, the agglomeration of ClermontFerrand (300000 inhabitants) being located $16 \mathrm{~km}$ East of the station. Meteorological parameters, including the wind speed and direction, temperature, pressure, relative humidity and radiation (global, UV and diffuse), atmospheric trace gases $\left(\mathrm{O}_{3}, \mathrm{NO}_{\mathrm{x}}, \mathrm{SO}_{2}, \mathrm{CO}_{2}\right)$ and particulate black carbon (BC) are monitored continuously throughout the year. Winter and summer temperatures vary typically from -10 to $+10^{\circ} \mathrm{C}$ and 5 to $25^{\circ} \mathrm{C}$ respectively. Westerly and northerly winds are dominant. During the November-April period, the access road to the station is restricted preventing from local contamination.

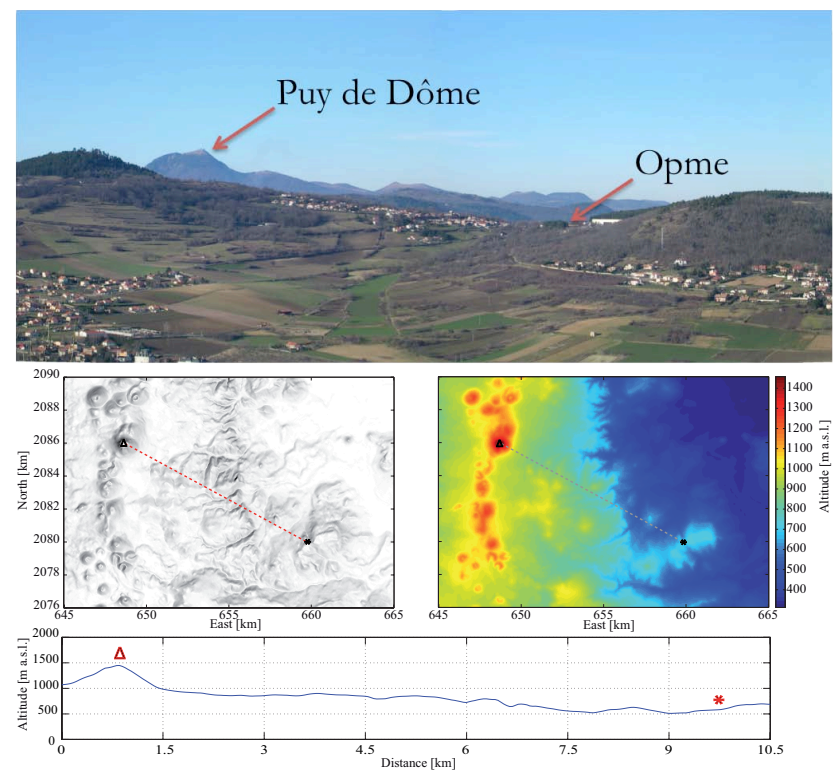

Fig. 1. Topographical view of the two measurement sites.

The Opme station is located around $12 \mathrm{~km}$ South-East of the PdD station $\left(45^{\circ} 42^{\prime} \mathrm{N}, 3^{\circ} 05^{\prime} \mathrm{E}, 660 \mathrm{~m}\right.$ a.s.l. $)$ in a rural area dominated by agricultural fields and forest. At this station the ultrafine aerosol and/or ion size distribution are/is monitored with an AIS or a NAIS depending on the period of the year. Basic meteorological parameters such as temperature, relative humidity and pressure are continuously measured. The geographical area of the two measurement sites is represented in the Fig. 1 (photography). As seen, the two sites are not separated by any topographical barrier (see the 3-D plots and the topographical profil, Fig. 1) so that air parcels can move free of constraint between the two sites (Fig. 1).

\section{Instrumentation}

\subsection{Particle measurement devices}

Because the PdD station is more than $50 \%$ of the time incloud, the aerosol sampling is performed through a whole air inlet (WAI) which ensures efficient sampling of both cloud droplets and interstitial aerosol in "in-cloud" conditions. The WAI samples air at $12 \mathrm{~m}$ above the ground through a heated inlet that avoids ice formation. Wind velocity around the inlet head is lowered by a wind-shield to ensure efficient sampling even at elevated wind speeds. Air is sucked into a $12-\mathrm{cm}$-diameter PVC tube at a flow rate of $30 \mathrm{~m}^{3} \mathrm{~h}^{-1}$ subsequently sub-sampled inside the PVC tube with a $5-\mathrm{cm}$-diameter stainless-steel tube ensuring isokinetic sub-sampling. The stainless-steel section of the inlet is equipped with a heated section to evaporate cloud 
droplets and to maintain the relative humidity of sampled air at about $50 \%$. Interstitial aerosols and evaporated cloud residues are sampled simultaneously at a constant relative humidity and can be compared in size regardless of the environmental conditions. Temperature never exceeded $25^{\circ} \mathrm{C}$ to limit aerosol volatilization. A SMPS (Scanning Mobility Particle Sizer), measured the particle number size distribution (10-400 nm) at the top of the puy de Dôme station through the WAI continuously since May 2005, with a twominute resolution. The SMPS is composed of a condensation particle counter TSI 3010 and a Differential Mobility Analyser (DMA) columns TSI-3081. The instrument data evaluation and the seasonal variation of the aerosol size distribution are described in details in Venzac et al. (2009). A separate short inlet was used for the AIS and NAIS sampling, directly through the station front facade, in order to avoid the re-combination of ions in the sampling line. The upper size-cut of large ions sampled through the AIS inlet is $10 \mu \mathrm{m}$ for a wind speed of $2 \mathrm{~m} \mathrm{~s}^{-1}$ and $2 \mu \mathrm{m}$ for; a wind speed of $5 \mathrm{~m} \mathrm{~s}^{-1}$ wind speed. As a result, few droplets should enter the inlet, except at wind speeds smaller than $5 \mathrm{~m} \mathrm{~s}^{-1}$ which is rare at the station (Venzac et al., 2007). The mobility distributions of atmospheric positive and negative ions are measured with the AIS (Airel Ltd., Mirme et al., 2007), providing the ion size distribution in the diameter range $0.8-42 \mathrm{~nm}$ for NTP-conditions (mobility range: 3.162 $0.0013 \mathrm{~cm}^{2} \mathrm{~V}^{-1} \mathrm{~s}^{-1}$ ). The AIS sampling principle is based on the simultaneous selection of 21 different sizes of atmospheric ions of each polarity (negative and positive) along two differential mobility analyzers and their subsequent simultaneous detection using electrometers in parallel. The sample flow rate of the AIS is $601 \mathrm{~min}-1$. The AIS sampling alternated with NAIS (Neutral clusters and Air Ion Spectrometer) sampling. The NAIS is similar to the AIS, with an additional possibility to measure total particles (neutral and charged particles). However, below $2 \mathrm{~nm}$, neutral particle measurements are not relevant since the post-filtering process cuts also the sampled newly formed particles (Asmi et al., 2009).

The data discussed in this paper are based on samplings achieved during more than three years from February 2007 to June 2010 for puy de Dôme site (AIS/NAIS \& SMPS) and from October 2008 up to June 2010 for Opme site (AIS/NAIS). Within this period, 952 days are available for the PdD station and 437 days for Opme station.

\subsection{LIDAR measurements}

In addition to in-situ measurements and in order to characterize the atmospheric layers structure, LIDAR measurements were performed from the roof of the Laboratoire de Météorologie Physique $\left(45^{\circ} 45^{\prime} \mathrm{N}, 3^{\circ} 6^{\prime} \mathrm{E}, 410 \mathrm{~m}\right.$ a.s.1.). The LIDAR used in this study is a Raymetrics Rayleigh-Mie LIDAR emitting at $355 \mathrm{~nm}$, with parallel and perpendicular polarization channels. The instrument provides profiles of vol- ume backscatter and extinction coefficients of aerosol particles, the depolarisation ratio, and water vapor mixing ratio. The LIDAR returns signals strongly dependent on height $z$ (in the case of a ground-based, vertically pointing lidar) and decreasing with $z^{2}$. Correcting the signal with $z^{2}$ thus removes the height dependence.

It is well known that aerosol particles are more numerous within the PBL than in the free troposphere (FT), so we assume that the PBL height is characterized by a break in the particle concentration. Thus we can infer that the light diffusion signal will be discontinuous between those two layers. As a consequence, the PBL height can be estimated as the height where the light diffusion regims starts to change, from a back-scattering signal dominated by the Mie diffusion (particulate regim) in the PBL to a back-scattering signal dominated by Rayleigh diffusion (gaseous regime) in the FT. An example is presented in Fig. 2. The position of the inflexion point is determined using fitting two different parts of the profile, assuming that the PBL upper boundary is located at the slope rupture point. A third layer could also be identified between the PBL and the FT. This layer is still strongly influenced by the PBL and lays between the upper limit of the PBL and the lower limit of the FT. It was thus defined as the interface layer. The height of this latter layer is also estimated using the divergence between the fit of the Rayleigh regime and the measurements assuming that its width is the height where abs $\quad\left(\right.$ Fit $_{\text {value }}-$ Measurements $)>$ (mean(Measurements) $-\operatorname{std}($ Measurements)). The method proposed here was compared to the WCT algorithm proposed by Brooks (2003), initially developed for marine boundary layer height retrievals. The calculated PBL height was found to be $32.2 \%$ higher on average when it was computed using our method. This difference comes from the fact that the WCT method tries to find the upper limit of the most concentrated aerosol layer (i.e. the start of the decrease of the Mie regime) whereas our method was build to find the transition from Mie diffusion regime to Rayleigh diffusion regime i.e. the transition from planetary boundary layer influenced layers to free tropospheric influenced layers. Compared to WCT and according to LIDAR contour plot, this procedure seems to be better adapted to the calculation of the PBL height in mountaineous area such as puy de Dôme.

\section{Results}

\subsection{Nucleation events at the puy de Dôme station}

\subsubsection{Events classification}

The classification of event days was performed visually using the daily contour plot of the ion size distribution evolution. Data were first categorized into three main classes: undefined, non-event and nucleation event days. Since different 

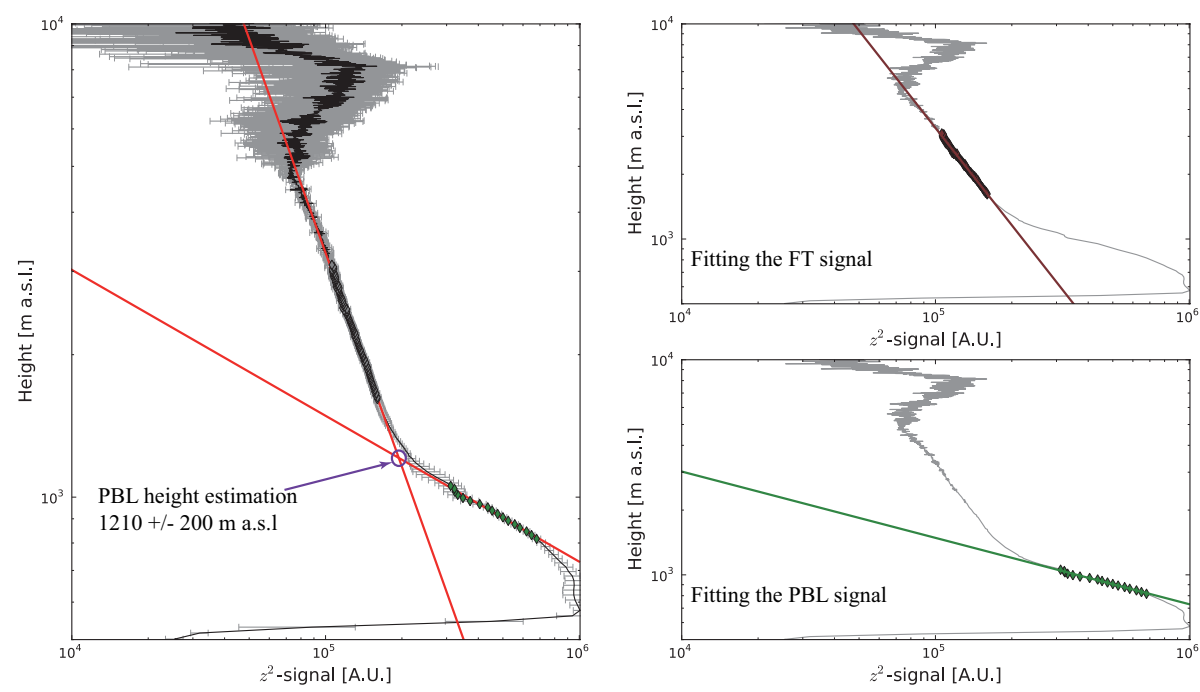

Fig. 2. Method for estimating the PBL, FT and interface layer limits. On the three graphical views, the mean $z^{2}$-signal profil during the nucleation event is represented. On the right hand side, fitting of the Rayleigh diffusion dominated regime (upper panel) and the Mie diffusion dominated regime (lower panel) are represented. The complete procedure with the PBL height estimation is represented on left hand side panel.

types of nucleation event can be observed, event days were classified into different classes (Ia, Ib, II and Bump) according to their quality and their applicability to a growth rate analysis (Hirsikko et al., 2005):

- Ia: Continuous growth of clusters $(0.5 \mathrm{~nm})$ to large particles $(\geq 20 \mathrm{~nm})$.

- Ib: These events are not as strong as class Ia events and sometimes cluster or intermediate growth are not clearly visible on the size distribution but the growth rate calculation remains possible.

- II: A clear event is identified but the growth from clusters to large particle is not regular and the shape of the size distribution is unclear. Further analysis of the new particle formation characteristics are complex or not possible.

- Bump: A burst of clusters is detected but it is not followed by a significant growth and particle formation. Different explanations are possible such as the total consumption of the condensing vapors or a change in the air mass.

Based on the long term continuous measurements, the seasonal variation of the nucleation events frequency at the $\mathrm{PdD}$ station is presented Fig. 3. Nucleation occurs around one third of the time at the PdD (30.8\%) which is in agreement with the previous study made by Venzac et al. (2007). Unfortunately, due to many discontinuities in the measurements, we cannot perform such an analysis for the Opme station. The observed seasonal variation (Fig. 3) is not very

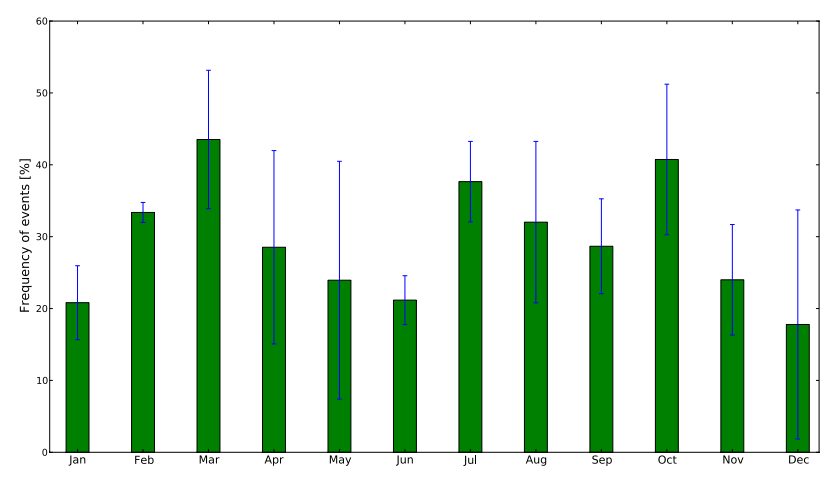

Fig. 3. Monthly mean nucleation frequencies at the puy de Dôme station.

pronounced but we can distinguish two maxima (one during early spring and the other one during the early autumn). At other sites where the frequency of nucleation events show a seasonal variation the maximal occurrence was usually observed during the spring and autumn seasons as well (Manninen et al., 2010) except for the Mt. Everest station (Venzac et al., 2008) where the maximal occurrence of nucleation events is during the summer. At Mt. Everest, authors explain this phenomenon as a result of the strong upslope wind that occurs during daytime in the summer and brings condensable vapours to the measurement site. The minimal occurrence frequency is always observed during winter months partly due to a lower photochemical activity (Venzac et al., 2008; Manninen et al., 2010; Boulon et al., 2010). 


\subsubsection{Nucleation rates calculations}

Different steps can describe the nucleation and subsequently growth processes. We chose 4 different boundary diameters $(1.3,3,7$ and $20 \mathrm{~nm})$ as representative of different growth steps so that growth rates were calculated between 1.3-3, 37 and 7-20 nm for (Ia) and (Ib) classes of event. A more detailed description of the growth rate calculation procedure can be found in Boulon et al. (2010). Average growth rates and their associated standard deviation (all average values are associated to their standard deviation) in each size class are respectively $3.22 \pm 0.25,6.52 \pm 0.20$ and $8.85 \pm 0.14 \mathrm{~nm} \mathrm{~h}^{-1}$, and the mean GR for the entire nucleation mode $(1.3-20 \mathrm{~nm})$ is $6.20 \pm 0.12 \mathrm{~nm} \mathrm{~h}^{-1}$. No significant seasonal pattern could be pointed out in the GR variations. The GR depends on (i) the chemical nature of the clusters and of the condensable vapours, (ii) the particle sizes. For a given constant condensable vapour concentration, the condensational dynamic equation (Dal Maso et al., 2002) predicts that the GR is decreasing with increasing particle diameters. The larger GR observed for larger particle diameters indicates that either condensing vapour concentrations increase with time, in parallel to the particle growth or/and the nature of condensing species evolves towards lower volatility compounds during the oxidation process as show by Aumont et al. (2005). Computed GRs from the puy de Dôme data are comparable to GRs computed for other mountain sites (i.e. Shaw, 2007; Nishita et al., 2008; Venzac et al., 2008; Boulon et al., 2010) even though those latter present a wide range of variation because of the wide range of local environmental conditions (e.g. condensable vapor sources such as the vegetation type, pollution incomings). Formation rates for charged $\left(J_{2}^{ \pm}\right)$and neutral $\left(J_{2}\right)$ aerosols were computed according to Eqs. (1) and (2) (from Kulmala et al., 2007):

$$
\begin{aligned}
J_{2}= & \frac{d N_{2-3}}{d t}+\text { Coag } \mathrm{S}_{2} \times N_{2-3}+\frac{f}{1 \mathrm{~nm}} \mathrm{GR}_{1.3-3} N_{2-3} \\
J_{2}^{ \pm}= & \frac{d N_{2-3}^{ \pm}}{d t}+\mathrm{Coag}_{2} \times N_{2-3}^{ \pm}+\frac{f}{1 \mathrm{~nm}} \mathrm{GR}_{1.3-3} \\
& N_{2-3}^{ \pm}+\alpha \times N_{2-3}^{ \pm} N_{<3}^{\mp}-\beta \times N_{2-3} N_{<2}^{ \pm}
\end{aligned}
$$

where $N_{2-3}^{ \pm}$is the ion number concentration (positive or negative ions) $\left(\# \mathrm{~cm}^{-3}\right.$ ) in diameter range from 2 to $3 \mathrm{~nm}$ and $N_{<x}^{ \pm}$is the ion number concentration below $x \mathrm{~nm}$. Coag $\mathrm{S}_{2}$ is the coagulation sink of $2 \mathrm{~nm}$ particles $\left(\mathrm{s}^{-1}\right) . \alpha$ and $\beta$ are respectively the ion-ion recombination coefficient and the ionneutral attachment coefficient and were assumed to be equal respectively to $1.6 \times 10^{-6} \mathrm{~cm}^{3} \mathrm{~s}^{-1}$ and $1 \times 10^{-8} \mathrm{~cm}^{3} \mathrm{~s}^{-1}$ (Tammet and Kulmala, 2005). The factor $f$ represents the fraction of the ion population in a size range from 2 to $3 \mathrm{~nm}$ which are activated for the growth. In this study we assumed this factor to be equal to unity. The time derivative of $N_{2-3}$ is directly obtained from the NAIS measurements. Coag $\mathrm{S}_{2}$ is derived from NAIS data. The mean formation rates of charged and neutral particles are $0.07 \pm 0.09$ respectively for positive ions, $0.07 \pm 0.08$ for negative ions, and $1.38 \pm 0.19$ for neutral species. From those results, the ion-induced nucleation (IIN) fraction was computed and the mean contribution of ions to the total formation rate was found to be in average $12.5 \pm 2.0 \%$. However, to estimate the error in formation rate calculation we compared the computed $J_{2}$ value with the one that can be derived from SMPS measurement and $J_{15}$ calculation using the relation given by (Lehtinen et al., 2007). The $J_{2}$ computed using the NAIS was found to be on average $2.4 \pm 1.7$ times higher than the ones derived from SMPS data. Thus the IIN fraction could be underestimated by the same factor, so the value provided is a lower limit of the IIN. At other continental high elevation sites, a high IIN contribution to the nucleation process was also pointed out: $21.8 \%$ for the Jungfraujoch high altitude station (3580 m a.s.l., Switzerland, Boulon et al., 2010) and $5 \%$ for Hohenpeissenberg (980 m a.s.l, Germany, Manninen et al., 2010) in comparison to boundary layer sites (Manninen et al., 2010 and Iida et al., 2006, 2.6 $\pm 2.8 \%$ in average on both studies). These results suggest that IIN is favoured at high elevations.

\subsubsection{The role of sulfuric acid}

Sulfuric acid concentrations were estimated using the parametrization proposed by Petäjä et al. (2009). This parametrization provide an estimation of the sulfuric acid concentration from the $\mathrm{SO}_{2}$ concentration and UVradiations. The parameterization uses a conversion parameter measured at the Hyytiälä boreal forest station, hence real $\mathrm{H}_{2} \mathrm{SO}_{4}$ concentrations at puy de Dôme could be different from our calculations, but their time variations should be respected. The difference in sulfuric acid concentrations calculated during nucleation event days and non-event days was tested with the Welch's t-test (t-test for two samples with unequal variance and unequal population). We found that the null hypothesis of identical average scores could not be rejected at the threshold of $5 \%$ (i.e. sulfuric acid concentrations are not statistically different between event and non-event days). Furthermore, no linear correlation was found between sulfuric acid concentrations averages (calculated over the 09:00-11:00 time period) and the particle formation rate $J(r=-0.4365)$. This result is in agreement with the analysis of the nucleation events occurring at the Jungfraujoch station (Boulon et al., 2010). It is likely that, at the puy de Dôme station and at the Jungfraujoch station, condensing compounds other than $\mathrm{H}_{2} \mathrm{SO}_{4}$, such as volatile organic compounds are involved in the new particle formation process. This assumption was also pointed out from chamber experiments by (Metzger et al., 2010). In order to test this hypothesis, we also tested different nucleation parametrizations involving sulfuric acid (Table 1, \#1) and we found that the formation rate parametrizations do not correlate with the observed $J$. Other parametrizations of charged 
Table 1. Formation rates calculated from different parametrizations.

\begin{tabular}{llr}
\hline ID. & Model & Pearson's $r$ \\
\hline$\# 1$ & $J_{2}=4.9 \times 10^{-07} \times \mathrm{H}_{2} \mathrm{SO}_{4}{ }^{\mathrm{b}}$ & -0.0855 \\
$\# 2$ & $J_{2}^{+}=1.9 \times 10^{-10} \times \mathrm{N}^{+} \mathrm{GlobRad}^{2, \mathrm{a}}$ & 0.1434 \\
$\# 3$ & $J_{2}^{+}=6.5 \times 10^{-18} \times \mathrm{N}^{+}\left(\mathrm{H}_{2} \mathrm{SO}_{4}\right)^{2, \mathrm{a}}$ & -0.1932 \\
$\# 4$ & $J_{2}^{-}=1.6 \times 10^{-10} \times \mathrm{N}^{-} \mathrm{GlobRad}^{2, \mathrm{a}}$ & 0.2328 \\
$\# 5$ & $J_{2}^{-}=6.7 \times 10^{-18} \times \mathrm{N}^{-}\left(\mathrm{H}_{2} \mathrm{SO}_{4}\right)^{2, \mathrm{a}}$ & -0.1877 \\
\hline
\end{tabular}

${ }^{a}$ from Nieminen et al. (2010), ${ }^{b}$ from Kerminen et al. (2010)

formation rate involving a preexisting cluster number concentration and (i) sulfuric acid (Table 1, \#3 and 5) or (ii) the global radiation as a proxy of photochemically induced nucleation (Table 1, \#2 and 4) were also tested. It appears that $J_{2} \pm$ models involving global radiations slightly correlate with observed $J_{2} \pm$. On the contrary, parametrizations that use sulfuric acid concentrations could not explain the observed charged formation rates. Those results corroborate the hypothesis that photochemical processes involving other compounds than $\mathrm{H}_{2} \mathrm{SO}_{4}$, such as organic vapour, are more relevant to describe observed particle formation rates at the puy de Dôme station.

\subsubsection{Air mass backtrajectories influence}

We investigated the impact of the air mass origin on the occurrence of a nucleation event using the three days air mass back trajectories computed with the HYSPLIT transport and dispersion model (Draxler and Rolph, 2003). Air masses were classified according to their geographical origin with a resolution of $1^{\circ} \times 1^{\circ}$. Since the terrain resolution used by Hysplit is the same as the native coordinate system inputs in Hysplit ( $1^{\circ}$ of resolution), the local terrain do not match the modelled terrain, which is much smoother. As a consequence, in a complex terrain such as the puy de Dôme area, Hysplit is less accurate to simulate local air mass motion such as topographical effects or local convection. Five different classes were created depending on the air mass' origin: Atlantic, African, Polar, Eastern and Western european air masses (the detailled classification can be found in Boulon et al., 2010). Tunved et al. (2005) estimated the aerosol turnover time of Aitken particles to be in the range of 1-2 days, while accumulation mode turnover time was estimated to be in the order of 2-3 days. Hence, we chose to compute three-day backtrajectories. Since the air mass origin and path to the measurement site does not differ significantly between 00:00 and 12:00, only results for 12:00 will be included in our analysis (Fig. 4). The calculation was done over all sampling days common to both sites, 437 days. Air mass back-trajectories and origins are respectively reported in Fig. 4 and Table 2.
Table 2. Origins of air masses reaching the puy de Dôme sampling site. 123 days could not be studied because of lack of data to run the Hysplit model.

\begin{tabular}{lrrr}
\hline $\begin{array}{l}\text { Air mass } \\
\text { origin }\end{array}$ & All days & Events & $\begin{array}{r}\text { Nucleating } \\
\text { ratio }\end{array}$ \\
\hline Atl. & 169 & 59 & 0.35 \\
Afr. & 19 & 5 & 0.26 \\
WE. & 105 & 36 & 0.34 \\
EE. & 14 & 3 & 0.21 \\
Pol. & 7 & 4 & 0.57 \\
\hline
\end{tabular}

The station is mainly under the influence of western air masses (i.e. from Atlantic and continental western Europe areas, Fig. 4). These two air mass types represent $87.3 \%$ of air masses reaching the sampling site and are associated to $88.8 \%$ of the nucleation events. Air masses from Africa and Eastern Europe represent $10.5 \%$ of total air masses and $7.5 \%$ of the total nucleation events. Polar air masses are very rare $(2.2 \%$ of the total air masses and $3.7 \%$ of the observed nucleation) but have the highest nucleating ratio (Table 2). Those results suggest that there is no link between nucleation events and air mass origin since nucleating ratios of all air masses are not significantly different. Furthermore, the vertical transport was also computed and $77.7 \%$ of the time air masses were found to be located between 0 and $1500 \mathrm{~m}$ a.s.l. while $22.1 \%$ of the time above $1500 \mathrm{~m}$ but below $2500 \mathrm{~m}$ a.s.l.. This later value is slightly less important in case of nucleation events $(21.3 \%)$. It can be seen that nonnucleating air masses originate from farther west suggesting they travel at high wind speed at higher altitude, and hence they could be less influenced by fresh boundary layer inputs. The seasonality of air mass types reaching the PdD station was studied by Venzac et al. (2009) who showed that western air masses reaching the puy de Dôme have travelled over longer distances during winter compared to summer. Hence another explanation for lower nucleation frequencies in more distant western air masses is because they coincide with winter conditions.

\section{Comparison of nucleation events between the two sites}

We investigated the cases when nucleation occurs (1) only at one station (puy de Dôme or Opme) and (2) at both sites. The data set was reduced to days for which data are simultaneously available at both sites. On 437 days when data was available at both sites, nucleation occurred on 161 days (i.e. $36.8 \%$ of the time). On those event days, 157 events ( $97.5 \%$ of detected events) were detected at the PdD station and 91 (56\% of detected events) at the low elevation station of Opme. Those first results show that the nucleation process is clearly enhanced at the altitude station (see Tab. 3). 95.6\% 

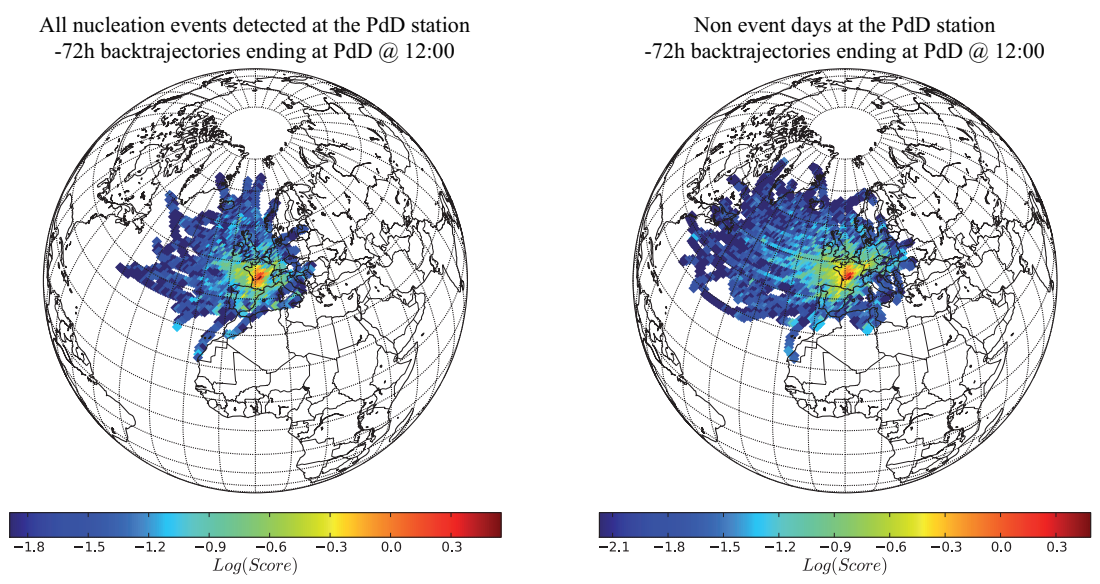

Fig. 4. Three days prior air mass backtrajectories computed with Hysplit model.

of events (87) detected at Opme station were also detected at the PdD station whereas only 4 events are detected at the low elevation station only, indicating that the new particle formation process usually occurs at a large vertical extent. On the contrary, considering the events detected at the elevation station of puy de Dôme, $44.5 \%$ of these events (70 events) were not detected at the lower altitude site. Based on those observations, all the nucleation events were classified into four different categories according if the event is detected (i) at the puy de Dôme station only (case "P"), (ii) at the Opme station only (case "O"), (iii) at both measurement sites and at the same time (case "Ds") or iv- at both sites but not at the same time (case " $\mathrm{D}_{\mathrm{D}}$ "). Average contour plots of each case are presented in Fig. 5. In the following section, we present a closer look at few atmospheric parameters corresponding to each case, in order to investigate the factors influencing one or the other configuration.

In the following, we investigate deeper the spatial extent of the nucleation through the study of the vertical structure of the atmosphere when the nucleation occur at the altitude site (cases "P", "DS" and "DD").

\subsection{Relationship to other atmospheric parameters}

Figure 6 shows a comparison of the different atmospheric parameters detected at the PdD station, averaged over all cases of nucleation event at the PdD station (Nuc, grey bar) or over all cases of non-event at the PdD station (Nev, grey bar). Data reported are parameters averaged over the 09:00-11:00 time period, which is assumed to correspond best to the nucleation period. Furthermore, we divided the data-set into two different sub-groups, according to "in-cloud" conditions at the puy de Dôme site. This procedure allowed us to analyze the influence of various atmospheric parameters independently of the influenced of clouds, which was previously shown to be important (Venzac et al., 2007).
Studied parameters (relative humidity, global radiation, black carbon, $\mathrm{SO}_{2}, \mathrm{O}_{3}$ and $\mathrm{NO}_{\mathrm{x}}$ ) present a higher variability during nucleation event days, compared to non-event days. The negative effect of a strong relative humidity is clearly observed as previously shown by Venzac et al. (2007), presumably because of the strong condensational sink that cloud droplets offer to the nucleating/condensing species. We also point out that the average $\mathrm{O}_{3}$ concentration is lower in case of event days compared to non-event days. The scavenging role of clouds on gases is revealed by the analysis of the $b$ part of Fig. 6 where it can be seen that atmospheric concentrations of $\mathrm{SO}_{2}$ and $\mathrm{O}_{3}$ are two times lower during "in-cloud" conditions. Going into more specific cases, Fig. 6 reveals that studied atmospheric parameters are roughly the same when a nucleation event is detected at the PdD station, no matter if the event is detected or not at the Opme station simultaneously (comparison of the grey-Nuc bar and orange bar). On the contrary, we show that the situation is very different when the nucleation occurs only at the low elevation site (Fig. 6, yellow bar). In fact, in case of $\mathrm{O}$ type events, we show that all measured parameters have the same median values as during a typical non-event day at the PdD station, i.e. higher relative humidity and higher ozone concentrations.

The condensational sink (CS) represents the loss of condensable vapours due to pre-existing particles per time unit (Pirjola et al., 1999). In a recent paper, Boulon et al. (2010) have shown that nucleation at the Jungfraujoch high altitude station could be linked to an increase of the condensational sink (CS) previous to the onset of the nucleation process, suggesting that the presence of condensing vapours probably associated to these high CS are driving the NPF events. In this study the CS could only be computed for the PdD station since no SMPS were available at the Opme site. The mean CS computed before the nucleation onset (06:00-09:00 time period) and when liquid water content (LWC) is lower than $0.02 \mathrm{~g} \mathrm{~m}^{-3}$ ("out-of-cloud" conditions) 

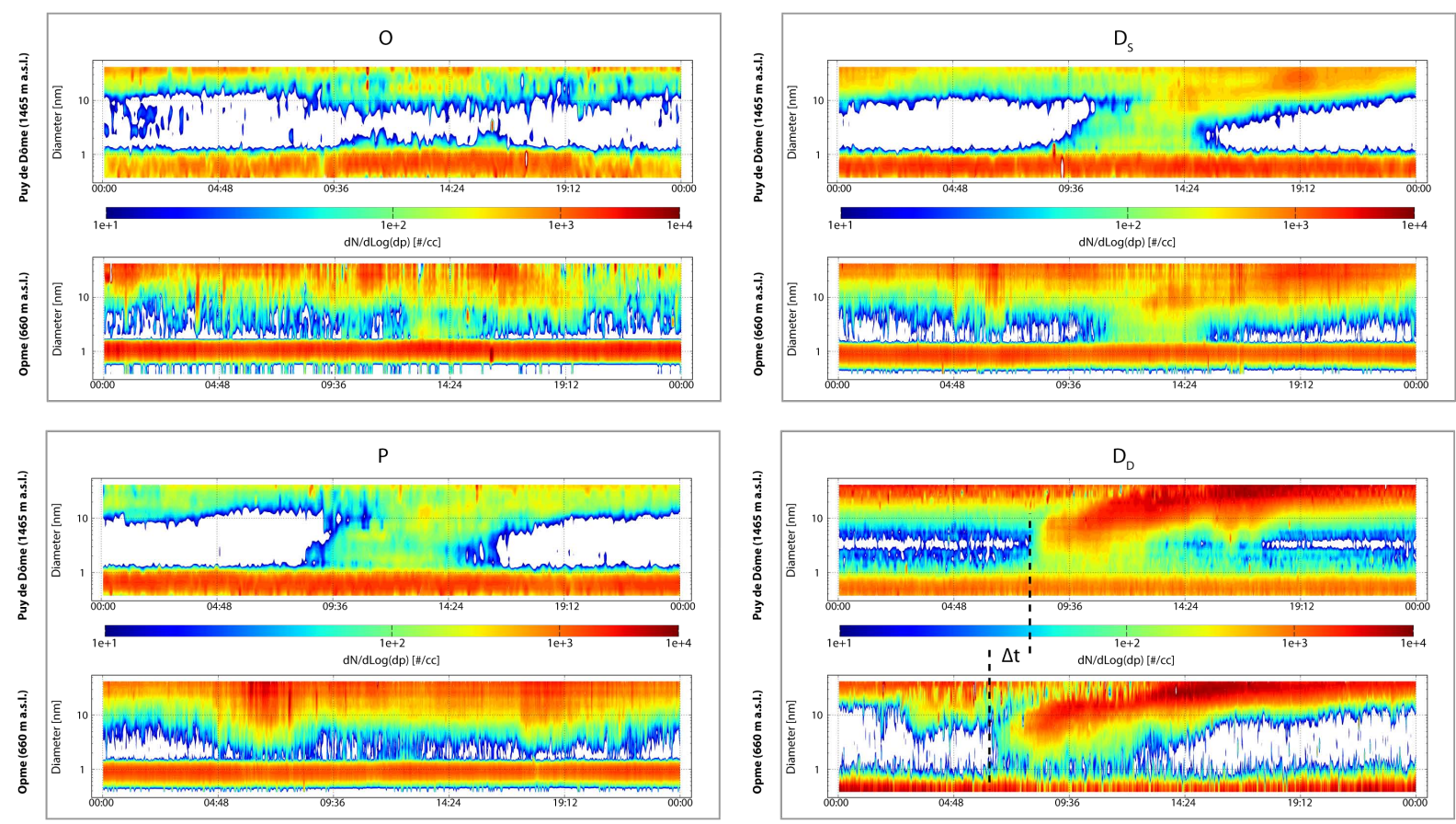

Fig. 5. Average temporal evolution of the negatively charged particle size distribution for the puy de Dôme (upper panels of grey boxes) and Opme (lower panels of grey boxes) in case of "O" events (upper left box), "P" events (lower left box), "DS" events (upper right panel) and "DD" (lower left box).

are reported in Fig. 7. We found that, on average, the CS is lower for event days $\left(3.73 \pm 0.11 \times 10^{-3} \mathrm{~s}^{-1}\right)$ than for non-event days $\left(5.17 \pm 0.15 \times 10^{-3} \mathrm{~s}^{-1}\right.$ ) (grey bars, respectively named Nuc and Nev), illustrating the inhibiting effect of a high CS on nucleation as often found in the literature. The CS calculated when the event takes place at both stations $\left(3.96 \pm 0.20 \times 10^{-3} \mathrm{~s}^{-1}\right.$, orange bar) is slightly higher than when nucleation occurs only at the higher elevation one $\left(3.50 \pm 0.11 \times 10^{-3} \mathrm{~s}^{-1}\right.$, green bar). Again, a strong difference is observed in case of "O" type events (Fig. 7, yellow bar). In those cases, the CS is two times larger than the one observed in case of nucleation at the PdD station (Fig. 7, Nuc). Our hypothesis is that in case of "O" events, the site is in the vicinity of clouds (as it will be shown later) and aerosols might still be hydrated, shifting the distribution to higher sizes and therefore increasing the condensation surface.

To summarize, at the PdD station, high condensational sinks seem to inhibit the nucleation process. This result is opposite to what Boulon et al. found at Jungfraujoch (JFJ). The JFJ is located at a higher altitude, $3580 \mathrm{~m}$ a.s.l., and surrounded by areas mainly covered by snow, thus presumably a more remote site, generally poor of condensing vapours, thus limiting nucleation. The puy de Dôme station is located at a lower altitude, surrounded by a coniferous forest and can be strongly influenced by the planetary boundary layer during the summer days (Venzac et al., 2009). As a consequence, it is likely that, at the PdD station, the condensable vapour concentration is not as a strong limiting factor to trigger the nucleation as at the JFJ station, because it is always present at relatively high concentrations due to the proximity of the vegetation. In this VOCs enriched environment, a low CS becomes the main condition for nucleation to occur. The CS calculated at the PdD station was found to be one order of magnitude higher than the at JFJ, and it is obviously limiting the occurrence of nucleation events at the site, confirming the relevance of our assumption.

In the following, each category of nucleation events $(\mathrm{O}$, $\mathrm{P}, \mathrm{D}_{\mathrm{S}}$ and $\mathrm{D}_{\mathrm{D}}$ ) will be studied separately. For each type of events, we will report the corresponding troposheric structure of the atmosphere using ground based LIDAR measurements and potential equivalent temperature, $\theta_{e}$, calculation according to the Bolton procedure (Bolton, 1980). Over the measurement period, LIDAR data are available for 132 days. When no LIDAR data are available, two air masses or atmospheric layers will be considered the same if (i) the two $\theta_{e}$ temporal evolutions are strongly correlated with each other during the nucleation process, and, (ii) the two equivalent potential temperatures are the same within the uncertainties of measurements. Uncertainties were computed using the classical error propagation theory, it was estimated to $\pm 4.7 \mathrm{~K}$ $(1 \times \sigma)$, i.e. $\Delta \theta_{e} \leq 4.7 \mathrm{~K}$. 

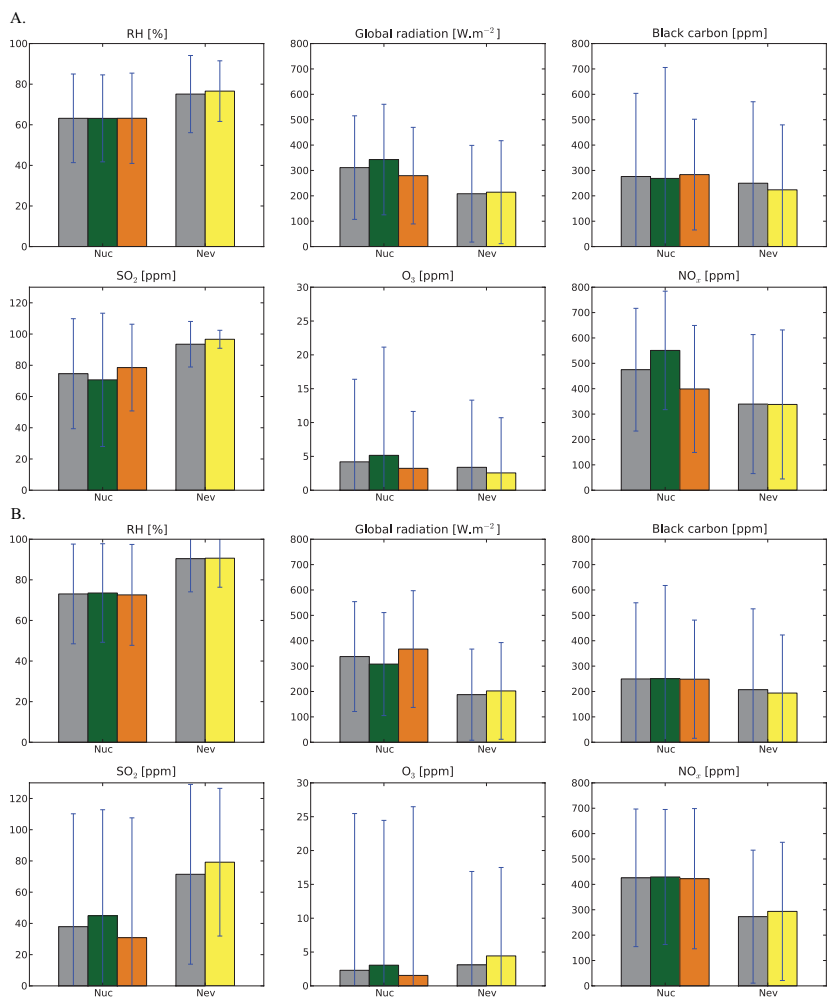

Fig. 6. Average and standard deviation of atmospheric parameters measured at the puy de Dôme station in case of event (Nuc, $N=157$ ) or non-event (Nev, $N=276$ ) days with or without cloud events filtering (repectively (A) and (B)) calculated over the 09:0011:00 time period. Grey bars represents the general case, when the nucleation is observed at the puy de Dôme station (Nuc) or not $(\mathrm{Nev})$. The green and the orange bars are respectively for a nucleation events that occur only at the puy de Dôme station $(N=70)$ and an event that occur at both measurement sites $(N=87)$. The yellow bar is for events that only occur at the Opme station $(N=4)$.

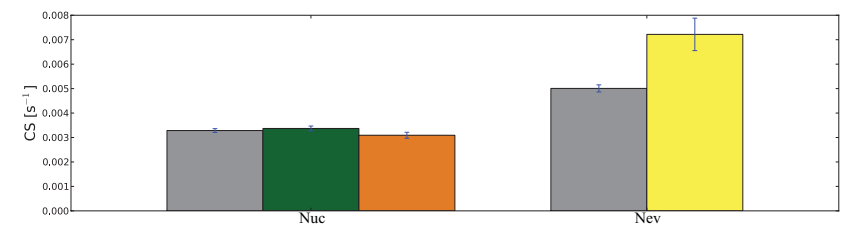

Fig. 7. Condensational sink average values with standard deviations for event days (Nuc) and non-event days (Nev) at the puy de Dôme station when LWC; $0.02 \mathrm{~g} \mathrm{~m}^{-3}$. Grey bars represents the general case, when the nucleation is observed at the puy de Dôme station (Nuc) or not $(\mathrm{Nev})$. The green and the orange bars are respectively for a nucleation events that occur only at the puy de Dôme station $(N=70)$ and an event that occur at both measurement sites $(N=87)$. The yellow bar is for events that only occur at the Opme station $(N=4)$.
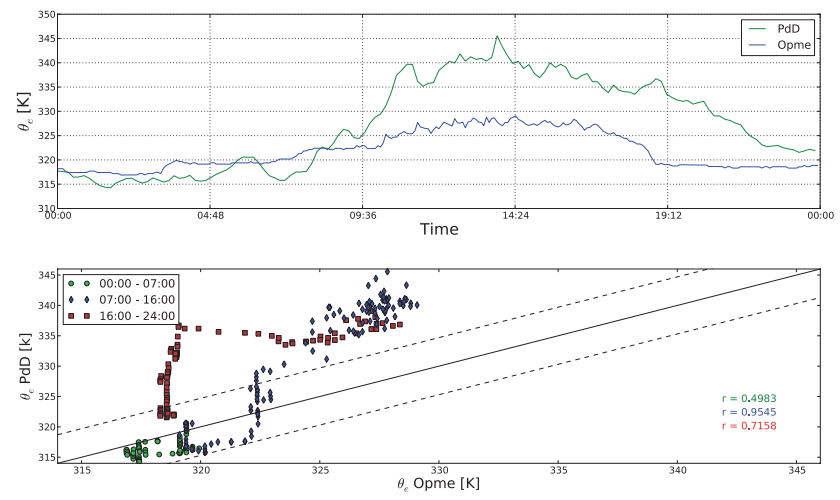

Fig. 8. Evolution of equivalent potential temperature, $\theta_{e}$ at both sites (upper panel) and the correlation between the two sites (bottom panel) in case of nucleation at Opme site (12 August 2007). On the bottom panel, the lines represent the uncertainty boundaries of the $\theta_{e}(1: 1)$ line.

\subsection{O cases: nucleation events at the Opme station only}

Nucleation events that occur only at the Opme station are very rare: only 4 events occurred on 437 observed days (4.4\% of the total observed nucleation events detected at Opme). Unfortunately, no LIDAR data are available for those events. As mentioned above, those cases present all characteristics in terms of atmospheric chemical properties of a non-event day for the puy de Dôme station: high relative humidity associated with a high CS. Going further in the analysis revealed that in each $\mathrm{O}$ case, when the nucleation is triggered at Opme station, clouds are detected at the PdD station (Fig. 5, case O) and likely interrupted the nucleation process through the scavenging of condensable vapours and/or pre-existing clusters by cloud droplets (Venzac et al., 2007). During all those events, Opme was cloud free because of its low elevation.

In the following, we analyze an example but it is representative of all four "O" cases. Also in terms of boundary layer dynamics, the same pattern is always observed. In case of "O" type events, Opme and PdD seem to be both within the $\mathrm{PBL}$ at the beginning of the nucleation process. This assertion is based on the comparison between the temporal evolution of the equivalent potential temperature $\left(\theta_{e}\right)$ at puy de Dôme and Opme. Figure 8 shows the temporal evolution of $\theta_{e}$ and the correlation of this thermodynamic tracer between the two sites at three different periods of the day (00:00 to 07:00, 07:00 to 16:00 and 16:00 to 00:00) and during the nucleation period (between 09:00 and 11:00). During the night and early morning, the two sites have the same $\theta_{e}$ but the low correlation $\left(r\left(\theta_{e}\right)=0.4930\right)$ indicates that the two sites are in different atmospheric layers. After 07:00 and until around 09:30, the two equivalent potential temperatures become equal and their evolution is strongly correlated $\left(r\left(\theta_{e}\right)=\right.$ 0.8391). After 09:30, the $\theta_{e}(\mathrm{PdD})>\theta_{e}(\mathrm{Opme})$ but their 
Table 3. Statistical data of nucleation event occurrences.

\begin{tabular}{lrrr}
\hline & PdD \& Opme & Only Opme & Only PdD \\
\hline Nb. events & 87 & 4 & 70 \\
Frequency & $19.9 \%$ & $0.91 \%$ & $16.0 \%$ \\
\hline
\end{tabular}

evolution is still strongly correlated $\left(r_{9: 30-16: 00}=0.9545\right)$. This could indicate that both sites are not located within the PBL unless this layer is strongly stratified thus inhomogeneous.

During the morning, the PdD station is in "in-cloud" conditions between 07:00 and 09:30, mean values of the relative humidity $(\mathrm{RH})$ and liquid water content (LWC) are respectively $100 \%$ and $0.089 \mathrm{~g} \mathrm{~m}^{-3}$, when the nucleation is triggered at Opme site. During the nucleation period, between 09:00 and 11:00, RH $=100 \pm 0.04 \%$ and $\mathrm{LWC}=$ $0.07 \pm 0.05 \mathrm{~g} \mathrm{~m}^{-3}$ in average which means that the station is mainly in "in-cloud" conditions while the nucleation is detected at the Opme site. Later during the day, the PdD station is still in "in-cloud" conditions or in the vicinity of clouds (RH and LWC between 07:00 and 16:00 are respectively $96.0 \%$ and $0.024 \mathrm{~g} \mathrm{~m}^{-3}$ in average). This type of event do not inform us on the spatial extent of the nucleation but two hypotheses could be formulated: (i) the spatial extent of the nucleation is very low and it occurs only within a small geographical area before all reactive and condensable species have been completely consumed, (ii) the nucleation could occur within the whole column in the PBL but condensable vapors have been scavenged by cloud droplets at the high altitude site. According to statistical analysis of the events repartition between the two sites, it is likely that the second hypothesis is the most probable. As we will show in the following, when the nucleation is triggered at Opme site, the phenomenon can usually be detected at the altitude station as well (87 events on 91 mesured at Opme station).

\subsection{P cases: nucleation events at the puy de Dôme station only}

This case represents $43.5 \%$ of the total number of nucleation events observed in this study (70 events on the 161 events, Table 3). Among these nucleation events, LIDAR data are available for 10 days.

The average daily time series of the cluster and particle size distributions at both sites is shown in Fig. 5, case "P". As seen, no nucleation event is detected at the Opme site, the two peaks of particle concentration seen at Opme station on early morning and at the end of the afternoon are due to traffic-related emissions. In Fig. 9 the temporal evolution of the equivalent potential temperature at both sites, $\theta_{e}$, is reported for a typical "P" case event (13 March 2009). All "P" case event days show the same pattern. The diurnal evolution of $\theta_{e}$, which is lower at the altitude site at night and
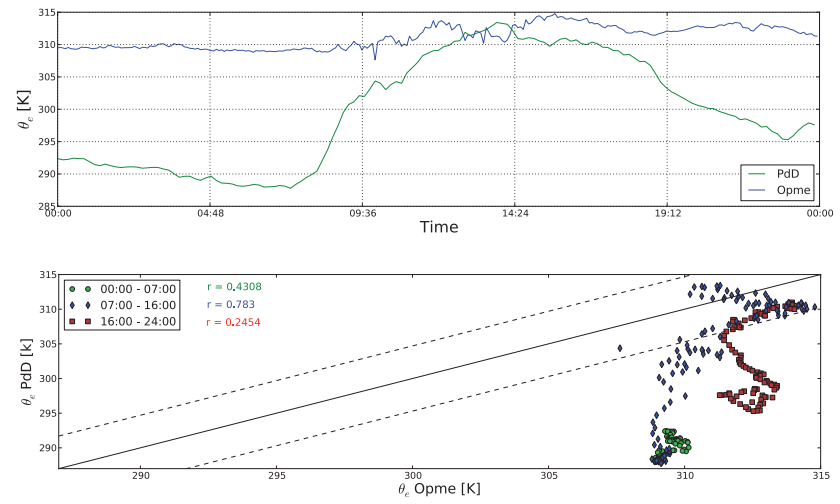

Fig. 9. Temporal evolution of equivalent potential temperature at both sites during a high altitude event ("P”, 13 March 2009).
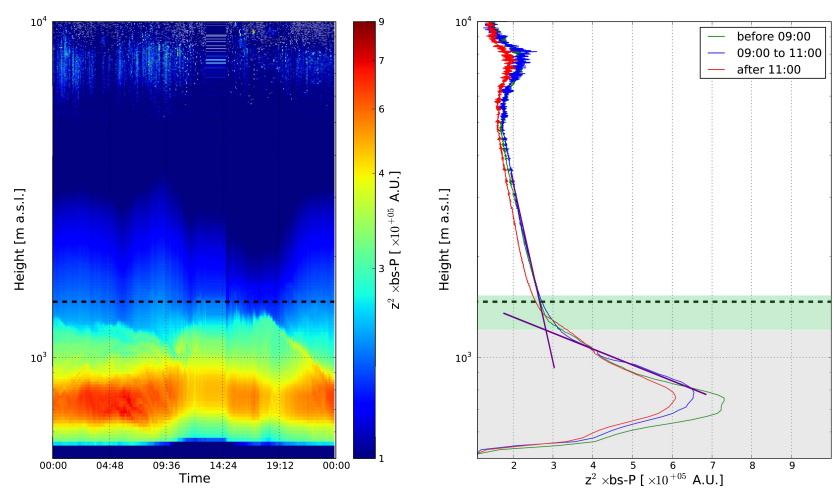

Fig. 10. Left panel: LIDAR $z^{2}$-signal evolution in arbitrary units (13 March 2009). Right panel: average LIDAR $z^{2}$-signal i- before 09:00 (green line), ii- between 09:00 and 11:00 (nucleation time) and iii- after 11:00. On both graphics, the black dot line represents the hight of the puy de Dôme station.

early morning (unstable conditions), suddenly increased until reaching the same value as at the low elevation site, within uncertainties. This clearly indicates a change in atmospheric thermodynamical properties $(T, \mathrm{P}, \mathrm{RH})$.

The evolution of $\theta_{e}$ between the two sites associated with a non-equality between the equivalent potential temperatures highlights that air parcels of each site are very weakly connected with each other during the nucleation process (in the case of 13 March 2009, $r\left(\theta_{e}\right)=0.3080$ and $\Delta \theta_{e}=$ $-7.2532 \mathrm{~K}$ ). This hypothesis is confirmed by the LIDAR measurements. The $z^{2}$ LIDAR back-scattering signal (we will name it the $z^{2}$-signal in the following), reported Fig. 10 (left panel) is consistent with this interpretation and clearly shows that the two sites are located within different atmospheric layers. A more precise analysis of the $z^{2}$-signal was performed and is reported on the right panel of the Fig. 10. It confirms that the Opme site is located within the PBL while the PdD is located at between the PBL and the FT, and more 

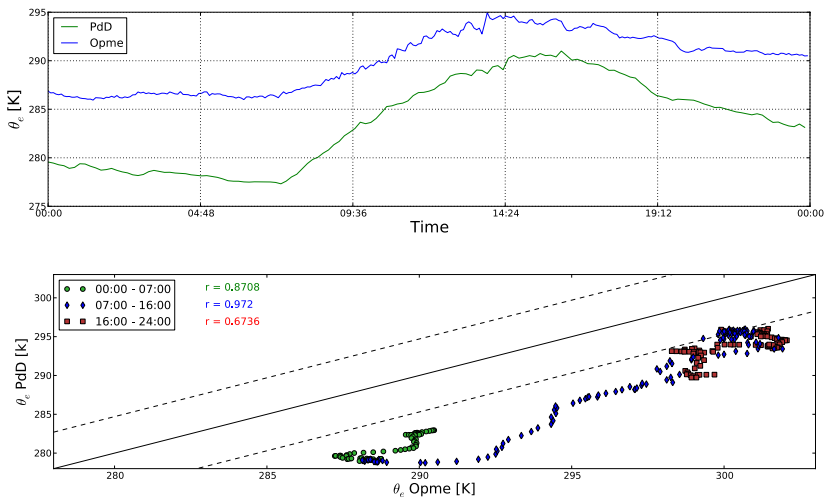

Fig. 11. Temporal evolution of equivalent potential temperature at both sites during a simultaneous nucleation event ("DS", 22 March 2009).

precisely above the upper boundary in what we defined as the interface layer. The average height of the PBL computed using our procedure between 09:00 and 11:00 for "P" cases is $1220 \pm 190 \mathrm{~m}$ a.s.l., hence confirming that the PdD station is located above the PBL during the nucleation process. By the end of the afternoon the LIDAR signal shows a subsidence of atmospheric layers when the thermic convection stops, leading to an atmospheric disconnection between the two sites. This is illustrated by an increasing of $\Delta \theta_{e}$ between the two sites and a decrease of the $\theta_{e}$ pearson correlation between the two stations.

\section{$5.4 D_{x}$ cases: nucleation events at both sites}

The " $\mathrm{D}_{\mathrm{x}}$ " case represents $54 \%$ of the total number of nucleation events observed in this study (87 events on the $161 \mathrm{ob}-$ served events, Table 3). Among these nucleation events, LIDAR data are available for 26 days. Two different sub-cases could be outlined: (i) the nucleation is triggered at the same time at both sites (47 events), and, (ii) the nucleation is first detected at the low elevation station (Opme) and after a variable time delay, the event is detected at the altitude site (PdD) (40 events).

\subsubsection{Simultaneous events $\left(D_{S}\right)$}

This phenomenon is observed on 47 days i.e. one third of the total nucleation events observed at the PdD station and 54\% of the "both sites events". As seen on the temporal evolution of the aerosol number-size distribution (Fig. 5, case $\mathrm{D}_{\mathrm{S}}$ ), the two events detected at both measurement sites start at the same time and present similar shapes and characteristics. In opposition to what we observed on the previous cases, here the evolution $\theta_{e}$ is well correlated along the day (Fig. 11) and especially during the nucleation process where the median Pearson's correlation is 0.739 for all $\mathrm{D}_{\mathrm{S}}$ events.
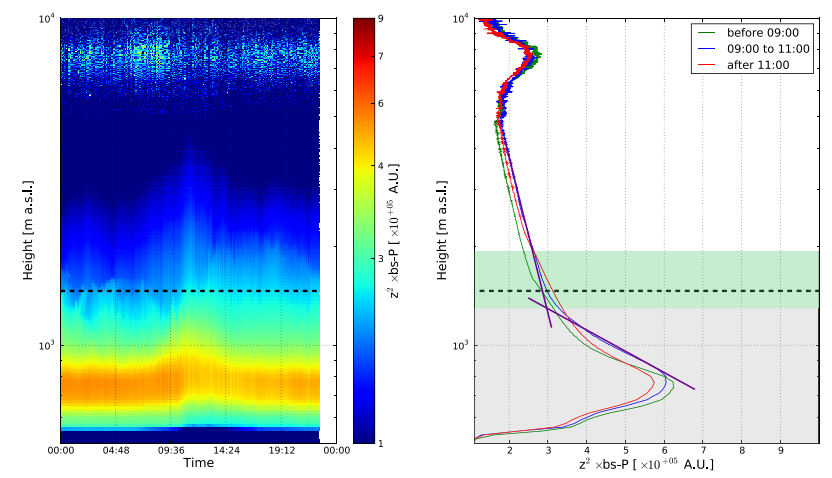

Fig. 12. Left panel: LIDAR $z^{2}$-signal evolution in arbitrary units in case of simultaneous nucleation event (22 March 2009). Right panel: average LIDAR $z^{2}$-signal i- before 09:00 (green line), iibetween 09:00 and 11:00 (nucleation time) and iii- after 11:00. On both graphics, the black dot line represents the hight of the puy de Dôme station.

The LIDAR signal analysis (Fig. 12) confirms what is deduced from the analysis of the temporal evolution of $\theta_{e}$. As seen in Fig. 12, the air parcels at the two sites are strongly connected: the PdD station is located inside the lower part of the interface layer while Opme station is within the planetary boundary layer. Moreover, during those cases, the PBL is not very polluted and well mixed. The nucleation events occur during the PBL development when the PBL influence on the interface layer is maximal.

In this case of simultaneous nucleation, we can conclude that nucleation occurs at the same time within the whole planetary boundary layer column. This means that all the elements required to trigger nucleation are homogeneously distributed within the low tropospheric column, from the interface layer to the ground level.

\subsubsection{Non simultaneous nucleation $\left(\mathrm{D}_{\mathrm{D}}\right)$}

In " $\mathrm{D}_{\mathrm{D}}$ " cases (40 events), the nucleation process occurs at both sites but it does not start at the same time at both stations. However, the temporal evolution of aerosols distribution (Fig. 5, $\mathrm{D}_{\mathrm{D}}$ ) shows that the nucleation events present very similar shapes and characteristics at both sites. This observation suggests that the two events are connected. An example of the evolution of theta is given in Fig. 13. All " $\mathrm{D}_{\mathrm{D}}$ " cases show the same theta evolution pattern. The non-correlated evolution of $\theta_{e}$ (Fig. 13) shows that the two sites seem to be located within two independent air parcels when the nucleation is triggered at the low elevation station $\left(r\left(\theta_{e}\right)=-0.1370\right.$ and $\left.\Delta \theta_{e}=-7.118 \pm 1.093 \mathrm{~K}\right)$. The median correlation of the equivalent potential temperature during the nucleation event for all $\mathrm{D}_{\mathrm{D}}$ events is 0.586 . This value is lower compared to the one observed for $\mathrm{D}_{\mathrm{S}}$ cases indicating that the atmospheric connection between the two sites is weaker. 

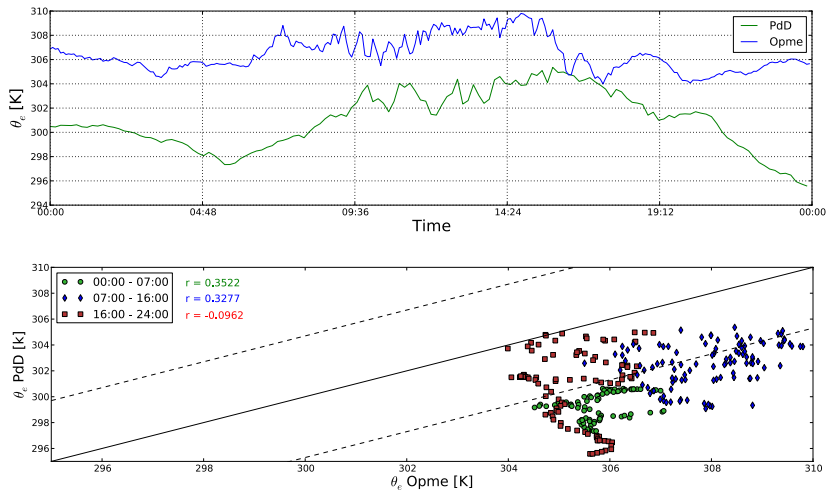

Fig. 13. Temporal evolution of equivalent potential temperature at both sites during a non-simultaneous nucleation event (" $\mathrm{D}_{\mathrm{D}}$ ", 21 May 2010).
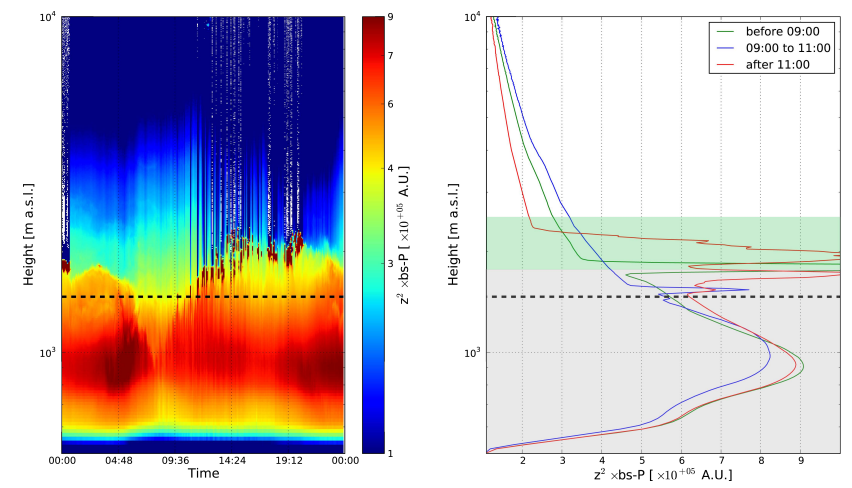

Fig. 14. Left panel: LIDAR $z^{2}$-signal evolution in arbitrary units in case of non-simulataneous nucleation event (21 May 2010). Right panel: average LIDAR $z^{2}$-signal i- before 09:00 (green line), iibetween 09:00 and 11:00 (nucleation time) and iii- after 11:00. On both graphics, the black dot line represents the hight of the puy de Dôme station.

On the contrary, LIDAR measurements (Fig. 14) indicate that the two measurement sites are located within the planetary boundary layer (the upper limit, in the case of 21 May 2009, was found to be $1700 \pm 515 \mathrm{~m}$ a.s.1.). The time delay of the nucleation at the altitude site could be due to a strong stratification of the boundary layer.

For all " $D_{D}$ " and " $D_{S}$ " events, we calculated the elevation of the top boundary of the PBL using the procedure we detailled Sect. 2.1.2. The average heights for " $D_{S}$ " and " $D_{D}$ " cases are respectively in average $1390 \pm 280$ and $2120 \pm 310$ ma.s.1. For the general " $D_{x}$ " cases, the average PBL extent is $1760 \pm 210 \mathrm{ma}$ a.s.l. which is significantly higer than in the "P" cases even though it shows a higher variability. The analysis of the potential temperature vertical gradient $\frac{\partial \theta}{\partial z}$ indicates that in both cases $\left(\mathrm{D}_{\mathrm{D}}\right.$ and $\left.\mathrm{D}_{\mathrm{S}}\right)$, the atmosphere is vertically stable. This indicates that the turbulent convec-
Table 4. Comparison of nucleation characteristics between $D_{x}$ and $P$ events.

\begin{tabular}{lrrr}
\hline & $\begin{array}{r}\mathrm{GR}_{1.3-20} \\
\left(\mathrm{~nm} \mathrm{~h}^{1}\right)\end{array}$ & $\begin{array}{r}J_{2} \\
\left(\mathrm{~s}^{-1}\right)\end{array}$ & $\begin{array}{r}\text { IIN fraction } \\
(\%)\end{array}$ \\
\hline P events & $5.86 \pm 2.75$ & $0.67 \pm 0.2$ & 32.0 \\
$\mathrm{D}_{\mathrm{x}}$ events & $6.15 \pm 2.55$ & $1.86 \pm 2.32$ & 6.2 \\
\hline
\end{tabular}

tion is not well developed at the time of the nucleation onset. This observation confirms that, in case of the simultaneous nucleation, all components required to trigger nucleation are homogeneously distributed within the PBL. During the $\mathrm{D}_{\mathrm{D}}$ cases, the PBL is much more polluted as it is revealed by the LIDAR measurements and the nucleation primarily occurs at low altitude before being detected at the high altitude suggesting a transportation of the nucleation process. In those particular cases, the nucleation process at the high altitude station is strongly linked to the PBL development because the nucleation is detected at the high altitude site when the PBL extend over the puy de Dôme measurement station. This suggests that during $\mathrm{D}_{\mathrm{D}}$ cases, components and conditions needed for the nucleation might be transported through advective motion of air parcels from low altitude to the high altitude station. This assumption is in agreement with the $\theta_{e}$ evolution at both site which present a temporal shift equal to the time delay observed on the nucleation event.

In case of events at both sites ( $D_{\mathrm{x}}$ events), no difference were found in GR and $J$ values between the two sites. This result supports the fact that the nucleation process is homogenous over the two sites for $D_{x}$ type of events. In case of the nucleation at the Opme station only, calculations of GR and $J$ were not possible because of the nucleation shape (calculations are possible for Ia and Ib cases). A larger data set will allow us to analyze and compare those events in the future. However, an analysis of GR and $J$ between $\mathrm{P}$ and $\mathrm{D}_{\mathrm{x}}$ events was conducted and reported on Table 4 . The main difference between the two types of events is the contribution of neutral species to the nucleation, which appears to be more than 5 times higher during "P" events while the charged formation rates remain roughly unchanged. This result highlights the variability of nucleation processes according to the altitude and atmospheric layers and support the assumption that the role of ions in the nucleation process could increase with the elevation (Yu et al., 2008).

\section{Conclusions}

We investigated the occurrence of nucleation and growth of new particles at a high elevation site, (puy de Dôme, center of France), through long-term measurements of clusters and particle size distributions. We first found that the nucleation frequency is quite high $(30 \%$ of observed days in 
average) and present a slight seasonal variation, with two maxima during early spring and autumn and a minimum during winter. From our observations, formation rates of $2 \mathrm{~nm}$ particles and their growth rate to larger size were computed using NAIS and AIS data. Average $J_{2}$ are respectively $\bar{J}_{2}=1.382 \pm 0.195 \mathrm{~s}^{-1}$, and average $\mathrm{GR}$ are $\overline{G R}_{1.3-20 \mathrm{~nm}}=$ $6.20 \pm 0.12 \mathrm{~nm} \mathrm{~h}^{-1}$. No seasonal variation of GR could be outlined at both sites. Different types of nucleation events defined by their spatial location and extent were pointed out:

- The "P" type corresponds to a nucleation event which is only detected at the high altitude station of the puy de Dôme ( $43.5 \%$ of the total observed events).

- The "O" type is defined by an event which occurs at the low elevation station of Opme only ( $2.5 \%$ of the total observed events).

- The " $D_{x}$ " cases represent $54 \%$ of the total observed events and are characterized by a nucleation event detected at both station at the same time ("DS" sub-cases) or with a time delay (" $\mathrm{D}_{\mathrm{D}}$ " sub-cases).

The analysis of the nucleation rates according to the type of event revealed that the role of neutral species decrease in case of "P" events compared to events that occur over the whole PBL ( $D_{\mathrm{x}}$ events). This points out that nucleation mechanisms could be different according to the altitude or atmospheric layers. Measurements of charged and neutral particles indicate that ion induced nucleation (IIN) contributed by $\mathrm{IIN}=12.49 \pm 2.03 \%$ to the total nucleation. Compared to other low elevation sites (IIN $=2.6 \pm 2.8$ ), the IIN calculated at the puy de Dôme is quite high but close to the one computed at European altitude sites ( $\overline{I I N}=15.10 \pm 6.96$ ) (Manninen et al., 2010; Boulon et al., 2010), suggesting that the ion contribution to nucleation is enhanced at high altitudes.

The relationships between available atmospheric parameters and the nucleation and growth occurrence were analyzed, showing little significant difference between event and non-event days for most atmospheric parameters except for relative humidity, ozone concentration and the condensational sink. This three parameters are all significantly lower in case of nucleation event at the puy de Dôme site (e.g. $\overline{\mathrm{CS}}_{\text {events }}=3.73 \pm 0.11 \times 10^{-3} \mathrm{~s}^{-1}$ while $\overline{\mathrm{CS}}_{\text {non-events }}=$ $\left.5.17 \pm 0.15 \times 10^{-3} \mathrm{~s}^{-1}\right)$. This latter observation does not corroborate the results reported from the Jungfraujoch high alpin site, where authors found that new particle formation events frequency surprisingly increases with the condensational sink (Boulon et al., 2010). Different condensable vapor/CS ratio, probably due to the local environment, are likely very different at the two stations (snow at the alpin station versus coniferous forest at the PdD station). Furthermore, we found that sulfuric acid does not seem to play a key role in the nucleation process at puy de Dôme, as also shown at the Jungfraujoch station, suggesting that at those two altitude sites, the nucleation is mainly influenced by other condensable vapors such as VOCs.
Combining the puy de Dôme measurements with measurements at the lower altitude station of Opme, we were able to investigate the vertical extent of the nucleation process in this rural mountainous area. In the puy de Dôme measurement area, the PBL development is less sharply defined than over flatlands due to complex topographic effects on atmospheric dynamics. The boundary layer development must be analyzed for each type of event: "O", "P" and " $D_{x}$ ". Since no LIDAR data were available for "O" type events, only "P" and " $D_{\mathrm{x}}$ " cases are analyzed. During "P" events, the puy de Dôme is located in the upper part of the interface layer, between the FT and the PBL, while the Opme station is located within the PBL. During those cases, the PBL is relatively clean (based on the LIDAR signal) and well mixed. The nucleation events occur during the PBL development when the PBL influence on the interface layer is maximal. On the contrary, it was found that in " $\mathrm{D}_{\mathrm{S}}$ " cases both sites are likely to be located in the planetary boundary layer or in the lower part of the interface layer. This latter result highlights that the nucleation occurs within the whole lower tropospheric column, from the interface layer to the ground level. During the nonsimultaneous events, the $\mathrm{D}_{\mathrm{D}}$ cases $(24.8 \%$ of total observed events), the PBL is much more polluted and the nucleation primarily occurs at low altitude before being detected after a various time delay at the high altitude suggesting a transportation of the nucleation process. In those particular cases, the nucleation process at the high altitude station is strongly linked to the PBL development since the nucleation is detected at the high altitude site when the PBL extends over the puy de Dôme measurement station.

The vertical extend of nucleation and growth events observed in this study exhibit some similarities with the one detected during previous airborne studies. During the EUCAARI field campaign, Crumeyrolle et al. (2010) have shown that the vertical extension of the new particle formation events do not exceed the top of the boundary layer and that most of the nucleated particle events observed have not been formed at the surface but must have nucleated elsewhere in the boundary layer suggesting that the nucleation process could be enhanced at higher altitudes. In a similar manner, during the IMPACT campaign (Wehner et al., 2010), authors have demonstrated that the nucleation likely occurs at high altitude, in turbulent zones of the residual layer.

Our findings demonstrate in a statistically relevant approach that the nucleation process is more frequent at high altitude site and occurs twice as frequently as actually detected in the PBL. Different assumptions can be made in order to explain why nucleation is more frequent at the high altitude site. The lower temperatures at higher altitudes increase the saturation ratio of condensable species (for a given concentration). Furthermore, LIDAR data show that the particle concentrations and hence the condensational sink decrease with the altitude. Although we do not know about the vertical gradient of condensable vapours concentrations, the two predicted gradients tend to favour the nucleation and growth processes. At higher altitudes 
Another possible reason why nucleation is more frequent at the $\mathrm{PdD}$ station might be mixing processes at the interface between the PBL and the FT. At this interface, turbulence might be increased due to the different properties of the two distinct atmospheric layers. As already proposed by Wehner et al. (2010), this turbulent mixing could lead to local supersaturation of condensable vapors which in turn could enhance the nucleation process. In addition to this statistical analysis, different vertical scales of nucleation have been pointed out: (i) the nucleation only occurs at high altitude above the mixed layers, between the PBL and the FT in the upper interface layer; (ii) the nucleation occurs at the same time along the whole the PBL and in the interface layer and (iii) the nucleation is triggered within the low PBL and then transported to highest altitude during the PBL development. Those observations suggest that the nucleation and subsequently growth process could have a very large vertical extent, at least up to more than $800 \mathrm{~m}$. However, this work only provide a lower boundary value since no measurements were available above the puy de Dôme station. Thus complementary airborne studies are needed especially to characterize what happens in the free troposphere when the nucleation is triggered in the planetary boundary layer and in the interface layer. Future campaigns should allow to investigate if the nucleation extends over the planetary boundary layer-free troposphere limit or if the phenomenon is vertically constrained as suggested by the work of Crumeyrolle and co-workers.

\section{Edited by: V.-M. Kerminen}

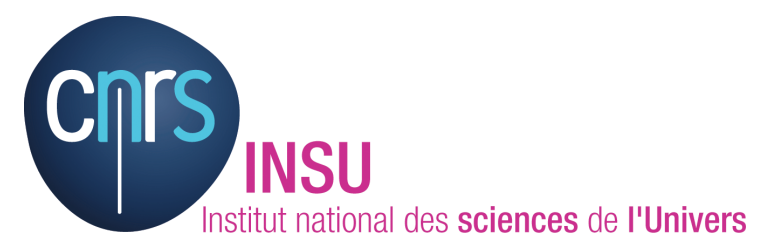

The publication of this article is financed by CNRS-INSU.

\section{References}

Asmi, E., Sipilä, M., Manninen, H. E., Vanhanen, J., Lehtipalo, K., Gagné, S., Neitola, K., Mirme, A., Mirme, S., Tamm, E., Uin, J., Komsaare, K., Attoui, M., and Kulmala, M.: Results of the first air ion spectrometer calibration and intercomparison workshop, Atmos. Chem. Phys., 9, 141-154, doi:10.5194/acp-9-141-2009, 2009.

Aumont, B., Szopa, S., and Madronich, S.: Modelling the evolution of organic carbon during its gas-phase tropospheric oxidation: development of an explicit model based on a self generating approach, Atmos. Chem. Phys., 5, 2497-2517, doi:10.5194/acp-52497-2005, 2005.

Bolton, D.: The Computation of Equivalent Potential Temperature, Mon. Weather Rev., 108, 1046-1053, 1980.

Boulon, J., Sellegri, K., Venzac, H., Picard, D., Weingartner, E., Wehrle, G., Collaud Coen, M., Btikofer, R., Flckiger, E., Baltensperger, U., and Laj, P.: New particle formation and ultrafine charged aerosol climatology at a high altitude site in the Alps
(Jungfraujoch, 3580 m a.s.l., Switzerland), Atmos. Chem. Phys., 10, 9333-9349, doi:10.5194/acp-10-9333-2010, 2010.

Brooks, I. M.: Finding Boundary Layer Top: Application of a Wavelet Covariance Tranform to Lidar Backscatter profiles, J. Atmos. Oceanic Technol., 20, 1092-1105, 2003.

Crumeyrolle, S., Manninen, H. E., Sellegri, K., Roberts, G., Gomes, L., Kulmala, M., Weigel, R., Laj, P., and Schwarzenboeck, A.: New particle formation events measured on board the ATR-42 aircraft during the EUCAARI campaign, Atmos. Chem. Phys., 10, 6721-6735, doi:10.5194/acp-10-6721-2010, 2010.

Dal Maso, M., Kulmala, M., Lehtinen, K. E. J., Mäkelä, J., Aalto, P., and O'Dowd, C.: Condensation and coagulation sinks and formation of nucleation mode particles in coastal and boreal forest boundary layer, J. Geophys. Res., 107(D19), 8097, doi:10.1029/2001JD001053, 2002.

Draxler, R. R. and Rolph, G. D.: HYSPLIT (Hybrid Single-Particle Langrangian Integrated Trajectory) Model access via NOAA ARL READY website (http://www.arl.noaa.gov/ready/hysplit4. html), NOAA Air Resources Laboratory, Silver Spring, MD, 2003.

Hamburger, T., McMeeking, G., Minikin, A., Birmili, W., Dall'Osto, M., O’Dowd, C., Flentje, H., Henzing, B., Junninen, H., Kristensson, A., de Leeuw, G., Stohl, A., Burkhart, J. F., Coe, H., Krejci, R., and Petzold, A.: Overview of the synoptic and pollution situation over Europe during the EUCAARILONGREX field campaign, Atmos. Chem. Phys., 11, 10651082, doi:10.5194/acp-11-1065-2011, 2010.

Hirsikko, A., Laakso, L., Hõrrak, U., Aalto, P., Kerminen, V.-M., and Kulmala, M.: Annual and size dependant variation of growth rates and ion concentrations in boreal forest, Boreal. Environ. Res., 10, 357-369, 2005.

Iida, K., Stolzenburg, M., McMurry, P. H., Dunn, M. J., Smith, J. N., Eisele, F., and Keady, P.: Contribution of ion-induced nucleation to new particle formation: Methodology and its application to atmospheric observations in Boulder, Colorado, J. Geophys. Res., 111, D23 201, doi:10.1029/2006JD007167, 2006.

Kerminen, V.-M., Petäjä, T., Manninen, H. E., Paasonen, P., Nieminen, T., Sipilä, M., Junninen, H., Ehn, M., Gagné, S., Laakso, L., Riipinen, I., Vehkamäki, H., Kurten, T., Ortega, I. K., Dal Maso, M., Brus, D., Hyvärinen, A., Lihavainen, H., Leppä, J., Lehtinen, K. E. J., Mirme, A., Mirme, S., Hõrrak, U., Berndt, T., Stratmann, F., Birmili, W., Wiedensohler, A., Metzger, A., Dommen, J., Baltensperger, U., Kiendler-Scharr, A., Mentel, T. F., Wildt, J., Winkler, P. M., Wagner, P. E., Petzold, A., Minikin, A., Plass-Dülmer, C., Pöschl, U., Laaksonen, A., and Kulmala, M.: Atmospheric nucleation: highlights of the EUCAARI project and future directions, Atmos. Chem. Phys., 10, 10829-1048, doi:10.5194/acp-10-10829-2010, 2010.

Komppula, M., Lihavainen, H., Hatakka, J., Paatero, J., Aalto, P., Kulmala, M., and Viisanen, Y.: Observations of new particle formation and size distributions at two different heights and surroundings in subarctic area in northern Finland, J. Geophys. Res., 108(D9), 4295, 2003.

Kulmala, M., Vehkamäki, H., Petäjä, T., Dal Maso, M., Lauri, A., Kerminen, V.-M., Birmili, W., and McMurry, P.: Formation and growth rates of ultrafine atmospheric particles: a review of observations, J. Aerosol Sci., 35, 143-176, 2004.

Kulmala, M., Riipinen, I., Sipilä, M., Manninen, H. E., Petäjä, T., Junninen, H., Dal Maso, M., Mordas, G., Mirme, A., Vana, 
M., Hirsikko, A., Laakso, L., Harrison, R., Hanson, I., Leung, C., Lehtinen, K. E. J., and Kerminen, V.-M.: Towards direct measurements of atmospheric nucleation, Science, 318a, 89-92, 2007.

Lehtinen, K. E. J., Dal Maso, M., Kulmala, M., and Kerminen, V.-M.: Estimating nucleation rates from apparent particle formation rates and vice versa: Revised formulation of the Kerminen-Kulmala equation, J. Aerosol Sci., 38, 988-994, doi:10.1016/j/jaerosci.2007.06.009, 2007.

Mäkelä, J. M., Riihelä, M., Ukkonen, A., Jokinen, V., and Keskinen, J.: Comparison of mobility equivalent diameter with KelvinThomson diameter using ion mobility data, J. Chem. Phys., 105, 1562-1571, 1996.

Manninen, H. E., Nieminen, T., Asmi, E., Gagné, S., Häkkinen, S., Lehtipalo, K., Aalto, P., Kivekäs, N., Vana, M., Mirme, A., Mirme, S., Hõrrak, U., Plass-Dülmer, C., Stange, G., Kiss, G., Hoffer, A., Moerman, M., Henzing, B., Brinkenberg, M., Kouvarakis, G. N., Bougiatioti, K., O’Dowd, C., Ceburnis, D., Arneth, A., Svenningsson, B., Swietlicki, E., Tarozzi, L., Decesari, S., Sonntag, A., Birmili, W., Wiedensohler, A., Boulon, J., Sellegri, K., Laj, P., Baltensperger, U., Laaksonen, A., Joutsensaari, J., Petäjä, T., Kerminen, V.-M., and Kulmala, M.: EUCAARI ion spectrometer measurements at 12 European sites - analysis of new-particle formation events, Atmos. Chem. Phys., 10, 79077927, doi:10.5194/acp-10-7907-2010, 2010.

Metzger, A., Verheggen, B., Dommen, J., Duplissy, J., Prevot, A. S., Weingartner, E., Riipinen, I., Kulmala, M., V., S. D., Carslaw, K. S., and Baltensperger, U.: Evidence for the role of organics in aerosol particle formation under atmospheric conditions, P. Natl. Acad. Sci. USA, 107, 6646-6651, doi:10.1073/pnas.0911330107, 2010.

Mirme, A., Tamm, A., Mordas, G., Vana, M., Uin, J., Mirme, S., Bernotas, T., Laakso, L., Hirsikko, A., and Kulmala, M.: A wide range multi-channel Air Ion Spectrometer, Boreal Environ. Res., 12, 247-264, 2007.

Nieminen, T., Paasonen, P., Manninen, H. E., Kerminen, V.-M., and Kulmala, M.: Parameterization of ion-induced nucleation rates based on ambient observations, Atmos. Chem. Phys., 10, 2169721720, doi:10.5194/acpd-10-21697-2010, 2010.

Nilsson, E. D. and Kulmala, M.: The potential for atmospheric mixing processes to enhance the binary nucleation rate, J. Geophys. Res., 103(D1), 1381-1389, doi:10.1029/97JD02629, 1998.

Nilsson, E. D., Rannik, U., Kulmala, M., Buzorius, G., and O'Dowd, C. D.: Effects of continental boundary layer evolution, convection, turbulence and entrainment, on aerosol formation, Tellus B, 53B, 441-461, 2001.

Nishita, C., Osada, K., Kido, M., and Matsunaga, K.: Nucleation mode particles in upslope valley winds at Mount Norikura, Japan: Implications for the vertical extent of new particle formation events in the lower troposphere, J. Geophys. Res., 113, D06 202, doi:10.1029/2007JD009302, 2008.
Petäjä, T., Mauldin, III, R. L., Kosciuch, E., McGrath, J., Nieminen, T., Boy, M., Adamov, A., Kotiaho, T., and Kulmala, M.: Sulfuric acid and $\mathrm{OH}$ concentrations in a boreal forest site, Atmos. Chem. Phys., 9, 7435-7448, doi:10.5194/acp-9-7435-2009, 2009.

Pirjola, L., Kulmala, M., Wilck, Bischoff, A., Stratmann, F., and Otto, E.: Formation of sulphuric acid aerosols and cloud condensation nuclei : An expression for significant nucleation and model comparison, J. Aerosol Sci., 30, 1079-1094, 1999.

Shaw, G. E.: Aerosols at a mountain top observatory in Arizona, J. Geophys. Res., 112, D07206, doi:10.1029/2005JD006893, 2007.

Stratmann, F., Siebert, H., Spindler, G., Wehner, B., Althausen, D., Heintzenberg, J., Hellmuth, O., Rinke, R., Schmieder, U., Seidel, C., Tuch, T., Uhrner, U., Wiedensohler, A., Wandinger, U., Wendisch, M., Schell, D., and Stohl, A.: New-particle formation events in a continental boundary layer: first results from the SATURN experiment, Atmos. Chem. Phys., 2, 1445-1459, doi:10.5194/acp-3-1445-2003, 2003.

Tammet, H. and Kulmala, M.: Simulation tool for atmospheric aerosol nucleation bursts, J. Aerosol Sci., 36, 173-196, 2005.

Tunved, P., Nilsson, E. D., Hansson, H.-C., Ström, J., Kulmala, M., Aalto, P., and Viisanen, Y.: Aerosol characteristics of air masses in norther Europe: Influences of location, transport, sinks, and sources, J. Geophys. Res., 110, D07 201, doi:10.1029/2004JD005085, 2005.

Venzac, H., Sellegri, K., and Laj, P.: Nucleation events detected at the high altitude site of the Puy de Dôme research station, France, Boreal Environ. Res., 12, 345-359, 2007.

Venzac, H., Sellegri, K., Laj, P., Villani, P., Bonasoni, P., Marioni, A., Cristofanelli, P., Calzolari, F., Fuzzi, S., Decesari, S., Facchini, M.-C., Vuillermoz, E., and Verza, G.-P.: High frequency new particle formation in the Himalayas, P. Natl. Acad. Sci. USA, 105, 15666-15671, 2008.

Venzac, H., Sellegri, K., Villani, P., Picard, D., and Laj, P.: Seasonal variation of aerosol size distributions in the free troposphere and residual layer at the puy de Dôme station, France, Atmos. Chem. Phys., 9, 1465-1478, doi:10.5194/acp-9-1465-2009, 2009.

Wehner, B., Siebert, H., Ansmann, A., Ditas, F., Seifert, P., Stratmann, F., Wiedensohler, A., Apituley, A., Shaw, R. A., Manninen, H. E., and Kulmala, M.: Observations of turbulence-induced new particle formation in the residual layer, Atmos. Chem. Phys., 10, 4319-4330, doi:10.5194/acp-10-4319-2010, 2010.

Yu, F., Wang, Z., Luo, G., and Turco, R. P.: Ion-mediated nucleation as an important global source of tropospheric aerosols, Atmos. Chem. Phys., 8, 2537-2554, doi:10.5194/acp-8-2537-2008, 2008. 